\title{
Computation of tidal conditions in the Thames by the initial value method
}

\author{
by \\ J. R. Rossiter, D.Sc. \\ and \\ G. W. Lennon, M.A.
}

Mr G. Lacey (Consultant, Sir M. MacDonald and Partners) wrote that the Authors were to be congratulated on a valuable paper of great interest to all concerned with model experiments. One manifest advantage of a numerical model was that it was full-scale; the vexed question of the choice of scale, and in particular the required exaggeration in the vertical scale was entirely obviated.

79. There was one feature common to both numerical and laboratory models. Irrespective of the type of model it was necessary to 'prove' it, i.e. secure correspondence between model phenomena and the observed phenomena of the prototype. If the laboratory worker failed to secure correspondence he might, in the last resort, be forced to modify the scales which he had at first adopted. As a general rule the laboratory model was improved by expedients such as smoothing its walls, or alternatively by increasing friction by baffles and other devices.

80. With the numerical model the same principles were involved, attempts being made to improve parameters so that the best possible agreement with observations was obtained. The Authors stated that the frictional parameter played a decisive part in determining the efficiency of a numerical model and it was in the friction term that the writer was most interested.

81. Three frictional parameters were tested in the model, the first being that of Chézy. Two factors were involved, the roughness or rugosity of the channel, and its size. It had long been established that for a given roughness the value of Chezy's $C$ increased with the size of the channel. This contention was confirmed by the values of $C$ in Table 1. Sections $10 \frac{1}{2}$ and $11 \frac{1}{2}$ gave somewhat anomalous figures and it was possible that this part of the river was in fact smoother than the lower reaches.

82. The second frictional parameter was that of Manning, and was superior to that of Chézy. The fit was by no means perfect. If sections $10 \frac{1}{2}$ and $11 \frac{1}{2}$ were omitted it would be noted that the value of $n$ diminished as the size of the channel increased. The writer had drawn attention to this phenomenon in $1930^{\circ}$ and recommended that the power of $2 / 3$ in the Manning equation should be increased to $3 / 4$ when the channels were in alluvium. Ven te Chow's researches confirmed the reduction of Manning's $n$ with increase in channel size.

83. Strickler had shown that the Manning equation, which was empirical, could be rationalized by writing it in the form

$$
V=\text { const. }(R / k)^{1 / 8}(g R S)^{1 / 2}
$$

in which $R$ was the hydraulic mean depth and $k$ the roughness height. The relative roughness number was thus introduced and it was possible to compare the Manning equation with the third parameter based on the Prandtl-yon-Karman mixing length hypothesis. If the third logarithmic equation were differentiated it would be found

- Proc. Instn civ. Engrs, 1965, 31 (May) 25-56. 
that for fine material involving high values of $(R / k)$ the exponent was very approximately equal to $1 / 6$. It was not surprising therefore that there was little choice between the second and third parameters.

84. It should be emphasized that in the two equations quoted, the relative roughness parameter $(R / k)$ applied to a fully turbulent channel, which in theory and in the experiments from which the logarithmic equation was derived, had a rigid boundary. There was no warrant for the assumption that an equation applicable to a moving alluvial boundary was identical in form. The moving boundary equation took the following form in metric units:

and in $\mathrm{ft} / \mathrm{sec}$. units

$$
V=\frac{1}{n_{\mathrm{a}}} R^{3 / 4} S^{1 / 2}
$$

$$
V=\frac{1 \cdot 346}{n_{\mathrm{a}}} R^{3 / 4} S^{1 / 2}
$$

85. In the following Table a trial had been made by assuming a constant value of $n_{\mathrm{a}}$ of 0.0265 for values of $R$ ranging from $10 \mathrm{ft}$ to $32 \mathrm{ft}$ and computing the corresponding values of Manning's $n$.

TABLE 5

\begin{tabular}{c|c|c|c}
\hline$R$ & $n_{\mathrm{a}}$ & $n$ & \multicolumn{1}{|c}{ Remarks } \\
\hline 3.2808 & 0.0265 & 0.0265 & depth of one metre \\
10.00 & 0.0265 & 0.0242 & lower limit depth \\
18.00 & 0.0265 & 0.0230 & \\
24.00 & 0.0265 & 0.0225 & \\
32.00 & 0.0265 & 0.0219 & upper limit depth \\
\hline
\end{tabular}

86. These figures were not incompatible with those given in Table 1. For reasons stated the writer thought it probable that sections $10 \frac{1}{2}$ and $11 \frac{1}{2}$ were smoother than the rest, and that curvature played a part in the somewhat high values of $n$ in sections $8 \frac{1}{2}$ and $9 \frac{1}{2}$. He suggested that it might be worth while testing the parameter $n_{\mathrm{a}}$ when an opportunity arose. The extrapolation to the North Sea would tax the Authors' ingenuity.

Dr D. M. McDowell (Consultant) wrote that he was glad to see this most thorough study of an application of numerical computations to the analysis of tidal propagation. It illustrated the high degree of accuracy which could already be achieved by this method. Mathematical models could not yet be used to examine the behaviour of flow in three dimensions in great detail, but they were very effective for studying mean tidal flow and level changes. It was now possible, in certain cases, to use mathematical models instead of physical models for the study of tidal propagation. Physical models could then be used for the study of more localized problems and, for a similar expenditure of time and money, might be built to a larger scale and with less scale distortion than was formerly possible.

88. The method of species analysis of tides was a useful contribution to the understanding of tidal behaviour in a particular tidal river. There was, however, one point regarding the results for the fourth-diurnal tide (Fig. 6) which was not clear to the writer. The amplitude of this species rose rapidly between sections 7 and 12 while that of the second-diurnal species fell. There was no marked phase change of the second-diurnal species, but the phase of the fourth-diurnal species was shown as changing through $360^{\circ}$ between sections 6 and 8 . This was an unexpected result. The implication was that the fourth-diurnal species was nearly in phase throughout the length of the river except for that lying between sections 6 and 8 . Between these 
sections it underwent a complete reversal of phase. There was nothing to indicate such a drastic change in the computed amplitudes at sections 6 and 8 . Would the Authors please amplify their comments on the behaviour of the fourth-diurnal species?

89. The Hydraulic Study Department of the Commissioners for the Port of Calcutta had obtained a solution of the dynamic equations for the River Hooghly, which was also largely inspired by the work of Otter and Day. ${ }^{3}$ Velocities in this river were rather higher than those found in the River Thames and it became clear to the writer that one effect not specifically mentioned by the Authors was important in the particular case of the Hooghly. This was the effect of velocity head on tide gauges due to their location. The effect was a function of velocity and often had the same sense, regardless of flow direction due to ebb or flood tides. It thus affected the fourth-diurnal component of the species analysis. A tide gauge situated on a bend in a river or in a region where currents differed from the mean flow, e.g., by a bridge abutment, would not read the mean tide level. In extreme cases, the error might reach the velocity head $\left(U^{2} / 2 g\right)$ but in general it was very much less.

90. On the assumption that the velocity was uniform across the width of the river, a correction for curvature might be made by using the equations:

or

$$
\begin{gathered}
h=h_{\text {outer }}-\frac{U^{2}}{2 g}\left[1-\frac{R_{2} \log _{\mathrm{e}} \frac{R_{1}}{R_{2}}}{R_{1}-R_{2}}\right] \\
h=h_{\text {inner }}+\frac{U^{2}}{2 g}\left[\frac{R_{1} \log _{\circ} \frac{R_{1}}{R_{2}}}{R_{1}-R_{2}}-1\right]
\end{gathered}
$$

A simpler equation which gave sufficiently accurate results was:

$$
\bar{h}=h \pm \frac{U^{2}}{2 g}\left[\frac{R_{1}-R_{2}}{R_{1}+R_{2}}\right]
$$

where $h$ is the surface height above datum level at the tide gauge, $\bar{h}$ is the mean river surface height above datum at the cross section, $R_{1}$ and $R_{2}$ are outer and inner radii of curvature of the flow, and $U$ is the mean velocity at the cross section.

91. The correction was usually quite small but it could have an important effect on the computations. The following example was given from a site where there is a sharp bend in the River Hooghly. Computations were done by a finite difference method to establish the Chézy coefficient throughout a typical tidal cycle. One of the tide gauges, situated at Akra, was on the outside of a sharp bend in the river. The outer radius of the flow was estimated to be 1420 metres while the inner radius was about 910 metres. The next tide gauge was located up-river at station Rajabagan on an almost straight reach. Computations were done using actual levels obtained at the two tide gauges and using approximate discharges computed by a finite difference method from the equation of continuity. They were then repeated using corrected values for $h$ at Akra. The results of calculation of the terms of the dynamic equation were given in Fig. 14 which showed values of $\partial h / \partial x$ and $U|U| / C^{2} A^{2} m$ obtained before and after correction of the gauge readings. The sudden changes of value at 11.15 were due to passage of a bore tide.

92. It was worth noting that the correction due to flow curvature would affect the fourth-diurnal component of tide because the correction was always in the same direction regardless of the direction of the flow. It might be that this would have a bearing on the small discrepancies on the fourth-diurnal component which the Authors had found in the case of the River Thames.

93. Turning now to the extension of computations to conditions which did not yet exist, a major difficulty occurred in all forms of model analysis, whether the model was physical or mathematical. It was usual for the tidal input at the seaward boundary of a model to be controlled to conform to the existing tide curves, either by the 


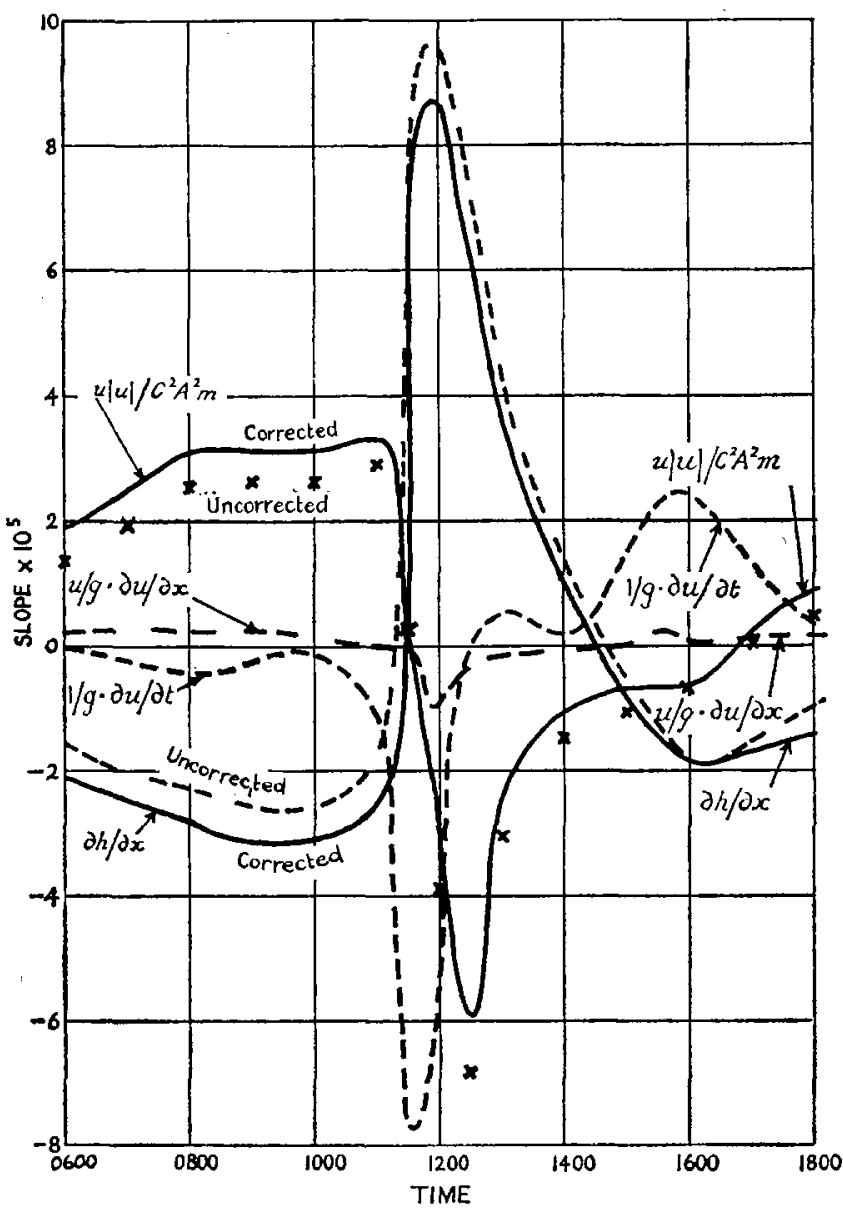

FIg. 14: TERMS OF DYNAMIC EQUATION FOR A REACH OF HOOGHLY SHOWING EFFECT OF CURVATURE OF FLOW ON GAUGE READINGS AT AKRA

mathematical input into the computer or by a servo-mechanism in the physical model. If the model was used to investigate the effect of major physical changes on tidal propagation, these would have an effect on tide levels at the mouth of the estuary, but the computer or the physical model was usually designed to ignore these changes at the 'tide generator'. There was then an error in the tidal input which would cause misleading results. This could be detected by re-calculating the tides with the seaward boundary in a different position. As the effect of the error was to cause a disturbance to be reflected back up-river from the 'tide generator', the position of the disturbance on a tide curve at a particular station would differ in time in each case and its presence could readily be seen.

94. This effect and the means of detecting it were pointed out to the writer by Mr Otter. Had the Authors any other suggestions for finding such errors or preventing their occurrence? 
Dr D. I. H. Barr (Senior Lecturer, Department of Civil Engineering, University of Strathclyde) asked if the Authors could elaborate on the effect of variation in density. If the conditions leading to the close agreement between the observed elevations and computed elevations shown in Fig. 10 were maintained except for the allowance for density gradient, would the computed level sequence in section 8-10 be lowered by up to $0.5 \mathrm{ft}$ throughout the tidal cycle, with better results obtained up-river?

96. The salinity distribution given by Inglis and Allen ${ }^{8}$ showed a fairly constant rate of change with distance throughout the tidal cycle. It seemed likely that a correlation of mean salinity against upstream volume for the Thames would show practically no variation throughout the tidal cycle for constant fresh water flow.

Mr N. V. M. Odd and Mr C. L. Robson (Hydraulics Research Station) found the Paper very interesting, because they had been using a similar mathematical model to predict the tidal hydraulics of the Nene Estuary. The computer programme used by the writers was also a continuation of the work of Otter and Day. It was written in Fortran for the Atlas computer of the Science Research Council at Chilton. It was a relatively simple matter to include the extra data necessary to calculate the second order terms because of the very large storage capacity of the machine.

98. The writers found that the convective acceleration was of some importance near the head of the estuary, and also found in common with the Authors that the salinity term improved the mean water levels while the magnitude of the resistance parameters was critical in determining the efficiency of the model. The writers would like to point out that the expression $-u / u / \psi(\bar{H})$ in equation (2) was only an approximation to the term $(1 / \rho) \times\left(\tau_{0} / R\right)$, where $\tau_{0}$ was the average shear stress on the wetted perimeter of the channel and $R$ was the hydraulic radius. The effectiveness of such an approximation depended on the relative importance of the resistance term, compared with the inertia terms.

99. Harder ${ }^{9}$ called the ratio between the average resistance term and the principal inertia term the dissipation factor.

$$
D_{s}=\frac{1}{8} \cdot \frac{g}{C^{2}} \cdot \frac{T}{R} \cdot u_{\max } \quad . \quad . \quad . \quad . \quad . \quad . \quad .
$$

where $T$ is the tidal period, $u_{\max }$ the current amplitude, $R$ the average hydraulic radius and $C$ Chézy's coefficient. The value of the dissipation factor determined the relative importance of the resistance term for different estuaries and different parts of the same estuary. The writers had used average values of $u_{\max }, R$ and $C$ for the Thames ${ }^{10}$ and the Nene. The average dissipation factor for the Thames was about 2 and for the Nene about 10 . However, the dissipation factor in the upper Thames might reach quite high values because both $C$ and $R$ decreased in those reaches of the river. When the dissipation factor exceeded about 2 , the resistance term began to distort the shape of the tidal wave and to reduce its speed of propagation up the estuary.

100. $\tau_{0}$, the average shear stress, was the sum of many different types of retarding forces on the wetted perimeter of the channel, for example, shear on the smooth part of the bed, shear on small roughness elements, form-drag on sand waves or boulders, form-drag resulting from rapid changes of cross-sectional area, drag on bridge piers, and shear resulting from secondary currents generated by bends in the river. The use of the term $-u / u / \psi(\bar{H})$ was based on the assumption that all these retarding forces were proportional to the square of the mean velocity, and that each coefficient varied with the depth of water in the same manner as the other coefficients.

101. When Hoffman ${ }^{11}$ did his tidal calculations for the ebb tide in the Great Ouse Estuary, he separated the retarding forces due to boundary roughness from the drag forces on local obstructions such as bridge piers. The $\psi(\bar{H})$ function in his boundary roughness term was $\psi /\left(K / H^{3 / 2}\right)$ compared with the Authors' $\psi\left(K / \bar{H}^{4 / 3}\right)$. In their 


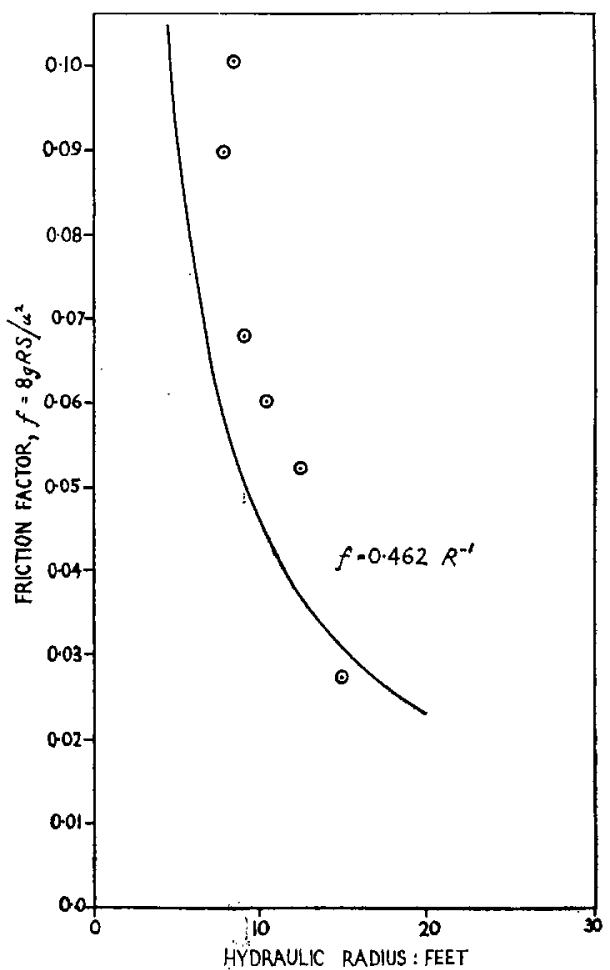

Fig. 15: EFfECt OF HydraUlic RADIUS ON FRICTION FACTOR: NENE ESTUARY, EbB TIDE

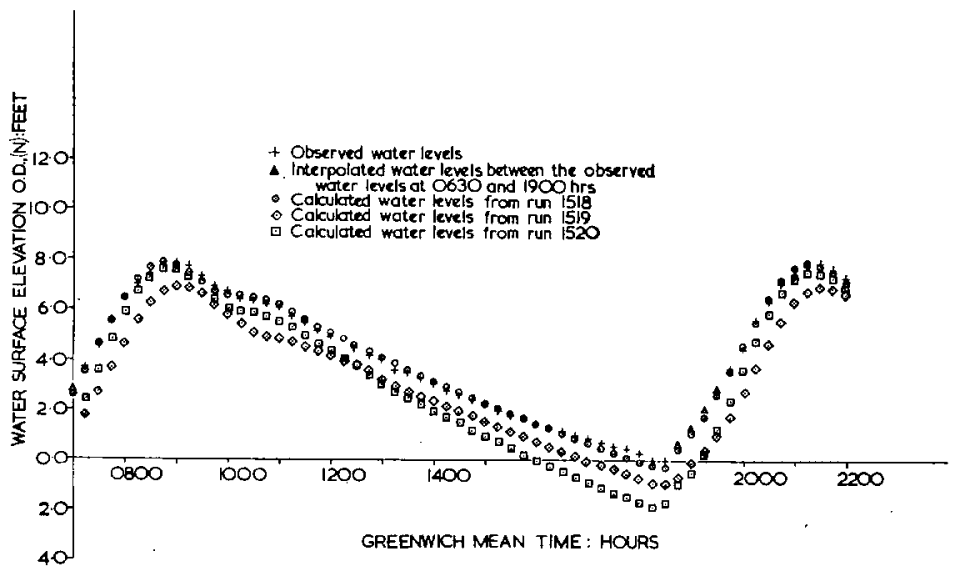

Fig. 16: Water levels in River Nene: Guyhirne Road Bridge, 22 September, 1964

Downloaded by [] on [26/04/23]. Copyright (C) ICE Publishing, all rights reserved. 
calculations the writers used the Darcy Weisbach formula because it had a dimensionless friction factor:

$$
f=\frac{8 g R S}{u^{2}} \text { and } \psi(\bar{H})=\frac{K}{R} \text { where } K=\frac{f}{8}
$$

All the other resistance formulae such as the Manning, Lacey, and logarithmic formulae simply made $K$ a function of $\left(k_{\mathrm{a}} / R\right)$, where $k_{\mathrm{s}}$ was some characteristic dimension of the irregularities in the channel. For example, the Authors found that the Manning formula, the same formula as the exponential approximation to the logarithmic law when the relative roughness lay between a value of 7 and 130, gave marginally the best result for the Thames estuary. ${ }^{12}$

102. The writers had the same problem as the Authors in deciding how $K$ should vary with the hydraulic radius. The writers tried to solve this problem by making some approximate calculations of the friction factor $f$ in the River Nene, using observed water levels and velocities on the ebb tide. An initial calculation showed that the term $(1 / g)(\partial u / \partial t)$ never exceeded $3 \%$ of the term $\partial z / \partial x$ for that part of the tide. The results of these calculations (circled points in Fig. 15) showed that the friction factor changed very rapidly with the hydraulic radius. The full curve in Fig. 15 was the optimized resistance function used for the same reach of the river as the observed friction factors. In the Authors' terms: $\psi(\bar{H})=\left(K / \bar{H}^{2}\right)$.

103. When the writers attempted to optimize the resistance parameters for each two-mile reach of the river, they followed the advice of the Authors and adjusted the $K$ values in the seaward reaches first before working upstream, but the writers were at first unable to make the mathematical model reproduce the observed tide curves. For example, the flood tide either arrived too late in the upper reaches of the estuary or high water was almost correct while low water was too low. Two such examples from test series 1500 are Runs 1519 and 1520 shown in Fig. 16. The tide curve refers to a station 16 miles upstream from the sea, the tidal range at the sea was $20.84 \mathrm{ft}$, and the freshwater discharge was 30 cusecs. At this position the river was $50 \mathrm{ft}$ wide at Newlyn Datum and the average bed level was $10 \mathrm{ft}$ below Newlyn Datum.

104. The writers then decided to investigate the changes of the resistance parameter $K$ during the flood tide. The averaged equation of motion could be used to determine the change in the friction parameter with the shape of the velocity profile

$$
\begin{aligned}
& \rho \frac{d u^{\prime}}{d t}=\gamma \frac{\partial z}{\partial x}-\frac{\partial \tau}{\partial y} \quad . \quad . \quad . \quad . \quad . \quad . \\
& \int_{0}^{H} \frac{\partial \tau}{\partial y} \cdot d y=\gamma \int_{0}^{H} \frac{\partial z}{\partial x} \cdot d y-\rho \int_{0}^{H} \frac{d u^{\prime}}{d t} \cdot d y \quad . \quad . \quad .
\end{aligned}
$$

where $H$ is the depth of water, $z$ is the water surface elevation, and $u^{\prime}$ is the velocity at a distance $y$ above the bed. For a channel $H$ becomes $R$, the hydraulic radius. In equation (12) $H$ can be replaced by $\delta$, the average boundary layer thickness, because when $\delta<y<H, \tau=0, y^{\prime}=$ constant, $(d u / d y)=0$

and

$$
\int_{\delta}^{u}\left(\gamma \frac{\partial z}{\partial x}-\rho \frac{d u}{d t}\right) d y=0 \text { for potential flow, }
$$

so

$$
\tau_{0}=\gamma R S\left(\frac{\delta}{R}\right)-\rho \frac{u^{2} \delta}{2 R} \int_{0}^{1} \frac{d\left(\frac{u^{\prime}}{u}\right)^{2}}{d\left(\frac{x}{R}\right)} \cdot d\left(\frac{y}{\delta}\right) \quad . \quad . \quad .
$$

The writers acknowledged that the above development was due to their colleague, Dr S. M. Yalin: a paper dealing fully with this subject was in preparation. 


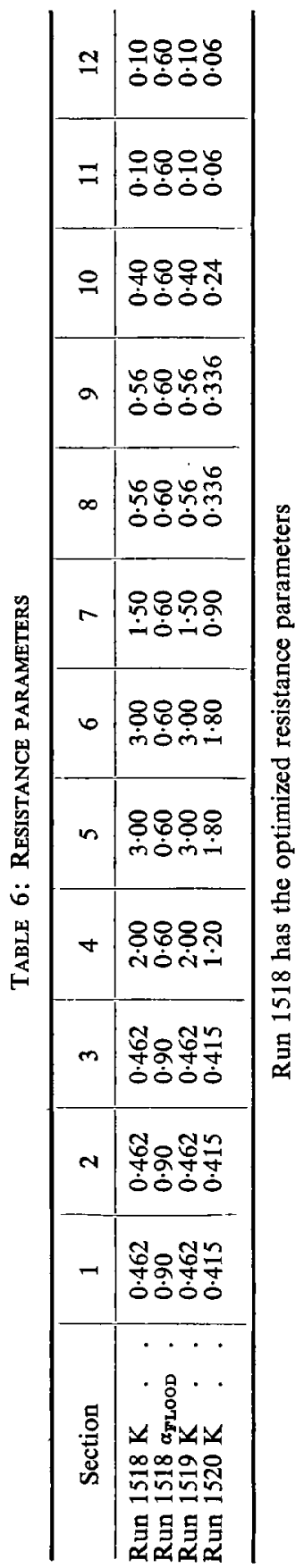

DISCUSSION ON COMPUTATION OF TIDAL CONDITIONS

\begin{tabular}{|c|c|c|c|c|}
\hline$\stackrel{\sim}{\sim}$ & $\begin{array}{l}n \\
m \\
\dot{0} \\
+\end{array}$ & $\begin{array}{l}\stackrel{n}{N} \\
\dot{+} \\
+\end{array}$ & $\begin{array}{l}8 \\
\dot{0} \\
+\end{array}$ & $\stackrel{\grave{r}}{\dot{r}}$ \\
\hline$\tilde{N}$ & 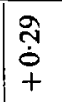 & $\begin{array}{l}+ \\
\dot{0} \\
+\end{array}$ & $\begin{array}{l}0 \\
\stackrel{0}{+} \\
+\end{array}$ & $\underset{\check{r}}{\stackrel{\leftrightarrow}{r}}$ \\
\hline శ્సి & 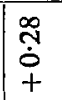 & $\begin{array}{l}\underset{0}{\dot{0}} \\
+\end{array}$ & $\begin{array}{c}\hat{0} \\
\dot{+}\end{array}$ & $\stackrel{\sim}{\sim}$ \\
\hline$\stackrel{\infty}{-}$ & $\begin{array}{l}\infty \\
1 \\
0 \\
+ \\
+\end{array}$ & $\begin{array}{l}\mathscr{0} \\
\dot{0} \\
+\end{array}$ & $\begin{array}{l}\stackrel{\infty}{\oplus} \\
\dot{+} \\
+\end{array}$ & $\stackrel{\vec{m}}{i}$ \\
\hline$\stackrel{0}{-1}$ & $\begin{array}{l}\hat{N} \\
\dot{0} \\
+\end{array}$ & $\begin{array}{l}\dot{t} \\
\dot{0}\end{array}$ & $\begin{array}{l}\hat{n} \\
\dot{0}\end{array}$ & $\begin{array}{l}\stackrel{0}{0} \\
\dot{\infty}\end{array}$ \\
\hline \pm & 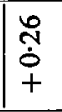 & $\begin{array}{l}m \\
+ \\
+\end{array}$ & $\stackrel{\infty}{0}$ & $\overrightarrow{\dot{\phi}}$ \\
\hline $\mathcal{I}$ & 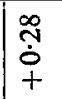 & $\begin{array}{l}\overrightarrow{0} \\
+\end{array}$ & $\begin{array}{l}\stackrel{9}{9} \\
\dot{0} \\
+\end{array}$ & $\stackrel{\overbrace{}}{\stackrel{9}{\Xi}}$ \\
\hline 음 & 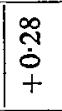 & $\stackrel{\infty}{\dot{0}}+$ & $\begin{array}{l}\stackrel{9}{+} \\
\dot{0} \\
+\end{array}$ & $\begin{array}{l}\stackrel{8}{0} \\
\dot{\Xi}\end{array}$ \\
\hline$\infty$ & 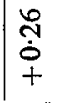 & $\begin{array}{l}n \\
\dot{0} \\
+\end{array}$ & $\begin{array}{l}\dot{J} \\
\dot{0} \\
+\end{array}$ & $\underset{ت}{\stackrel{+}{0}}$ \\
\hline 0 & $\begin{array}{l}a \\
\dot{0} \\
+\end{array}$ & $\frac{a}{\dot{0}}$ & $\begin{array}{l}\vec{m} \\
\dot{0}\end{array}$ & 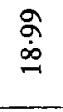 \\
\hline$\nabla$ & $\underset{+}{\stackrel{+}{+}}$ & $\begin{array}{l}\frac{t}{0} \\
+\end{array}$ & $\begin{array}{l}\tilde{1} \\
\dot{0} \\
+\end{array}$ & $\begin{array}{l}\tilde{n} \\
\stackrel{\Omega}{\Omega}\end{array}$ \\
\hline $\mathrm{N}$ & $\begin{array}{l}0 \\
\dot{0} \\
+\end{array}$ & $\begin{array}{l}\infty \\
0 \\
\dot{0} \\
+\end{array}$ & $\underset{\dot{\phi}}{+}$ & 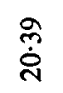 \\
\hline
\end{tabular}

Downloaded by [] on [26/04/23]. Copyright @ ICE Publishing, all rights reserved. 
105. If

combining the constants

$$
\begin{aligned}
\gamma R S & =K^{\prime} \rho u^{2}, \\
\tau_{0} & =K \frac{\delta}{R} \rho u^{2}
\end{aligned}
$$

where $K$ is a function of $(k s / R)$ then $1 / \rho . \tau_{0} / R$ is approximated by $-\alpha u / u / \psi(\bar{H})$ where $\alpha=(\delta / R)$, the ratio between the average boundary layer thickness and the hydraulic radius.

106. Velocity profiles measured in the River Ouse and the River Mersey showed that the velocity on the flood tide reached a maximum at approximately mid-depth, while the velocity increased right up to the water surface on the ebb tide. The writers therefore reduced the resistance parameters on the flood tide by a factor of 0.5 for a trial run. The final optimized value for $\alpha$ on the flood tide was 0.60 for all but the three deepest reaches near the sea where $\alpha=0 \cdot 90$. The best run for a spring tide was Run 1518 (Fig. 16). The hump on the ebb tide was the reflexion from the head of the estuary nine miles upstream. Table 6 showed the resistance parameters used in Runs 1518,1519 , and 1520 . The writers would welcome the Authors' comments on whether they might use this sort of approach if they wanted a more accurate reproduction of the water levels near Richmond Lock.

107. Before the writers tried to optimize the resistance parameters, they included both the salinity term and the convective acceleration term. Unlike the Authors, the writers had decided to include the variation of $\partial \rho$ with time and distance, because there were large changes in the position of the salinity intrusion in the River Nene during a tidal cycle. Fortunately, salinity data was available both as a function of time and position. These calculations showed the same order of improvement as was found by the Authors (see Tables 7 and 8).

108. The writers included the convective acceleration term by a method developed by Rose $^{12}$ who differentiated the equation of continuity to get an expression for $u(\partial u / \partial x)$

$$
\frac{u \partial u}{\partial x}=-\frac{5}{A} \cdot \frac{\partial z}{\partial t}-\frac{u^{2}}{A} \cdot \frac{\partial A}{\partial x}
$$

This method had the advantage that velocities were not averaged over very long distances in the river. The drawbacks were that more data was needed for the flow areas at the $H$ mesh points and water surface widths at the $U$ mesh points. It was also necessary to know $z_{m+1, n+1}$.

109. The extra data were easily dealt with because of the large storage capacity of the Atlas computer. The second point was dealt with by storing values of $z$ and $u$ for the whole of each tidal iteration ignoring convective acceleration for the first two tides, after which it was included. The whole calculation with five run-in tides took 1.2 minutes on the computer. It was hoped that a better method could be

TABLE 8: IMPROVEMENT IN AGREEMENT WTTH PROTOTYPE ON INCLUSION OF CONVECTIVE ACCELERATION AND SALINTTY TERMS

All the calculations had the same optimized resistance parameters as Run 1518
Water levels at Guyhirne feet, O.D. (N)

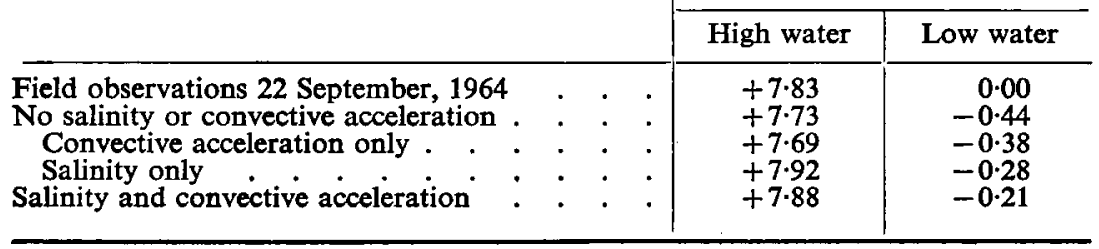


developed involving an initial guess for $z_{m+t . n+t}$ and iterating between the two finite difference equations so that it would be possible to include the term immediately, without a two tide run-in. The differences in water levels between the calculations with and without the convective acceleration term were shown in Tables 7 and 8 .

Mr A. L. Andrews (Messrs Edwards, Clendon and Partners, Wellington, N.Z.) wrote that after considering many computational techniques for solving the problem of propagation of shallow water waves in river channels, the writer found that an indirect numerical method had important advantages. For brevity, the method as set out below was applicable only to uniform breadth channels without tributaries and without salinity and temperature gradients, though extensions could easily be made to account for these factors.

111. When the governing equations had the form

$$
\begin{aligned}
& \frac{\partial}{\partial x}[u(h+\eta)]=-\frac{\partial \eta}{\partial t} \quad \text { (continuity) } \\
& u \frac{\partial u}{\partial x}+\frac{\partial u}{\partial t}=-g \frac{\partial \eta}{\partial x}+F_{\mathbf{x}} \text { (dynamic) }
\end{aligned}
$$

where $\eta=\eta(x, t)$ is the height of the free surface above a level reference plane, $h=h(x)$ is the depth of water below the reference plane, $u=u(x, t)$ is the flow velocity, $F_{x}=F_{x}(x, t)$ is the friction force per unit mass in the $x$ direction.

112. If $c=c(x, t)=\sqrt{ } g(h+\eta)$ was introduced, then

$$
\begin{aligned}
& \frac{\partial c}{\partial x}=\frac{g}{2 c}\left[\frac{\partial \eta}{\partial x}+\frac{\partial h}{\partial x}\right] \\
& \frac{\partial c}{\partial t}=\frac{g}{2 c} \frac{\partial \eta}{\partial t}
\end{aligned}
$$

Substitute in each of the governing equations and add and subtract these to yield a new pair:

$$
\begin{aligned}
& {\left[\frac{\partial}{\partial t}+(u+c) \frac{\partial}{\partial x}\right] \cdot(u+2 c-m t)=F_{\mathbf{x}} \quad . \quad . \quad .} \\
& {\left[\frac{\partial}{\partial t}+(u-c) \frac{\partial}{\partial x}\right] \cdot(u-2 c-m t)=F_{\mathbf{x}} \quad . \quad . \quad . \quad .}
\end{aligned}
$$

in which $m / g=d h / d x$.

113. Each of these could be cast in the form of ordinary differential equations by putting $d x / d t=u+c$ in the first and $d x / d t=u-c$ in the second:

$$
\begin{aligned}
& \text { for } \\
& \frac{d x}{d t}=u+c, \quad \frac{d}{d t}(u+2 c-m t)=F_{\mathrm{x}} \\
& \text { for } \\
& \frac{d x}{d t}=u-c, \quad \frac{d}{d t}(u-2 c-m t)=F_{x}
\end{aligned}
$$

114. With these relationships one could draw families of curves $\phi_{1}$ for which $d x / d t=u+c$ and $\phi_{2}$ for which $d x / d t=u-c$ in the $x, t$ plane, if values of $u$ and $c$ for all $t$ were known at one gauging station, say $x=0$. (Equally satisfactory would be values of $u$ and $c$ for the whole reach of the stream for any $t$, say $t=0$; but this was less likely to be known.) It might happen that only $u$ or $c$, but not both, was known. In such a case, the writer found it satisfactory to deduce the unknown from Lorentz's linear resistance theory. While the linear resistance theory did not give a good prediction for $x \gg 0$ in channels so frictive that there was pronounced attenuation of the wave, it was found to give quite acceptable 'starter' values for $u(o, t)$ from known values of $c(0, t)$.

115. If $r$ and $s$ were two points in the $x, t$ plane, for each of which $u$ and $c$ were 
known, and $t_{\mathrm{r}}>t_{\mathrm{B}}$, then the member of the family $\phi_{1}$ passing through $r$ would intersect the member of $\phi_{2}$ passing through $s$ at $n$, and the co-ordinates of $n$ were given by: -

$$
\begin{aligned}
& x_{\mathrm{s}}-x_{\mathrm{n}}=(u+c)_{s}\left(t_{\mathrm{r}}-t_{\mathrm{n}}\right) \\
& x_{\mathrm{r}}-x_{\mathrm{n}}=(u-c)_{\mathrm{r}}\left(t_{\mathrm{s}}-t_{\mathrm{n}}\right)
\end{aligned}
$$

provided the increments were small enough for the member of $\phi_{1}$ and of $\phi_{2}$ each to be replaced by a short straight line segment. The values of $u_{\mathrm{n}}$ and $c_{\mathrm{n}}$ at $x_{\mathrm{n}}, t_{\mathrm{n}}$ were:

$$
\begin{gathered}
u_{\mathrm{n}}=\frac{1}{2}\left[(u+2 c)_{\mathrm{s}}+(u-2 c)_{\mathrm{r}}+\left(F_{\mathrm{x}}-\alpha g\right)\left(2 t_{\mathrm{n}}-t_{\mathrm{r}}-t_{\mathrm{s}}\right)\right] \\
c_{\mathrm{n}}=\frac{1}{4}\left[(u+2 c)_{\mathrm{s}}-(u-2 c)_{\mathrm{r}}+\left(F_{\mathrm{x}}-\alpha g\right)\left(t_{\mathrm{r}}-t_{\mathrm{B}}\right)\right]
\end{gathered}
$$

when $F_{\mathbf{x}}$ was the frictive force for unit mass (which might be calculated either at $r$ or $s$ ) and $\alpha$ was the bed slope.

116. With this information the $x, t$ plane could be mapped with characteristics $\phi_{1}$ and $\phi_{2}$, and at each intersection values of $u$ and $c$ would be known. As the water depth was $c^{2} / g$, contours of velocity and depth could also be mapped, thus giving a complete solution for the tide on one diagram. Presentation of data in this form was most useful.

117. This method was applied to predict results of model runs in which friction effects were high and initial wave amplitudes were large compared with the steady state depth, so that the attenuation was much more severe than that which occurred on the Thames model (Fig. 5). The initial mesh points along the $t$ axis were $1 / 20$ of the total period apart, and the prediction was so good that it was probable that a much coarser mesh would yield acceptable results. These investigations were done some sixteen years ago, when the writer did not have computer facilities available, so that the simplification inherent in this method was more important than it would be now. Nevertheless, the Authors may care to consider the possible merits of the method for machine computation.

The Authors, in their reply, first expressed their thanks for the several detailed and constructive comments which had been made by the contributors to the discussion. They were particularly appreciative of the opportunity to note the views of hydraulic engineers on the relative merits and defects of the terms which had been adopted in the numerical model, and were grateful to have further evidence that the optimized values of parameters produced in the course of proving the model were in accordance with engineering experience.

119. The Authors agreed with Mr Lacey that this, together with subsequent experience of similar experiments, confirmed the view that the use of the numerical model technique did not allow one to dispense with a proving process. The necessity to optimize parameters on the basis of a comparison with observations remained. This point had some bearing upon the adoption of revised forms of the frictional term contained in the equation of motion. The modification of the Manning equation suggested in $\S 84$ was most interesting and would appear likely to produce optimized values for the frictional parameter in which the variation with distance would be less marked. However, in practical terms, it was necessary to acknowledge that no real progress would be made for the Thames itself. It was unlikely that the model output would be significantly improved and in the absence of a perfectly constant parameter a new optimization or proving process would be required when attention was switched to another estuary. Nevertheless, the Authors valued Mr Lacey's advice on the question of the frictional term and would undertake tests of the modified version of Manning's equation in due course.

120. Mr Lacey had referred also to difficulties of extrapolation of the model calculations into the North Sea, and might be interested to learn of subsequent developments in this respect. The current Thames model had been extended seawards as far as Harwich, bounded to the south and east by a hypothetical bank following natural stream lines. The problem of providing input representative of a 
point some 16 miles off-shore from Harwich might soon be solved on the basis of the analysis of tidal observations made at Sunk Head Tower, but in the interval some progress had been made in an investigation of the effects of wind stress applied to the water surface in the estuary and also in a study of interaction between tide and surge. In these latter cases input data for the extended model had been provided by the use of a separate model of the extension from Southend to Harwich. This subsidiary model accepted input at Southend and output data appropriate to the off-shore point at the outer extremity. This technique had established' a typical spring tide cycle over approximately three days which had been used in the studies of interaction and wind effects. Meanwhile a colleague at the Tidal Institute, N. S. Heaps, was developing a two-dimensional sea model which could be made to represent the entire British waters contained upon the continental shelf. Other colleagues were concerned with the matching of such a two-dimensional network with a one-dimensional river model so that a family of models of different types and scales might be established which were, nevertheless, mutually compatible. An investigation of models using varying mesh lengths and even non-rectangular grid systems was being conducted.

121. The Authors were appreciative of Dr McDowell's remarks, and considered his suggestions regarding the use of complementary physical and mathematical models to be of great importance.

122. The distribution of the quarter-diurnal tide in the upper reaches of the Thames was, without doubt, a complex matter. It should first be stated that analyses of periods of observation not reproduced in the Paper all indicated that marked changes took place, both in amplitude and phase, in the region of sections 8 to 10 (Greenwich to Chelsea). Some examples were given in Fig. 17, from which it would be seen that not all the plots of $Z 4$ and $\delta 4$ were of precisely the same shape as those given in Fig. 6. The data for Fig. 6 were chosen, in fact, to illustrate the most extreme case encountered.

123. Quarter-diurnal tides, along with all other shallow water species, were continuously generated in every compartment of a shallow coastal area or estuary. Thus
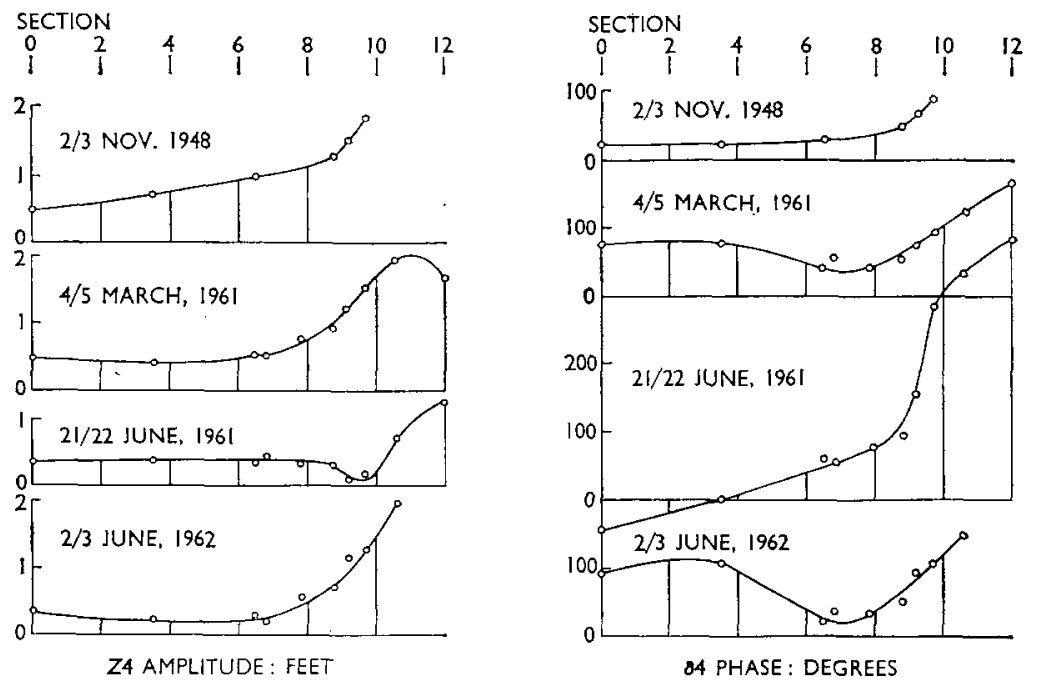

Fig. 17: Distribution OF OBSERVED QUARTER-DIURNAL TIDE ALONG THE THAMES ON VARIOUS DAYS 
the incoming quarter-diurnal at the mouth would be propagated to the head but would be continuously modified in its progress. In terms of the harmonic notation the laws of generation of shallow water tides were, as yet, only qualitatively understood; what was certain was that they were highly dependent upon local topography.

124. Fig. 6 might therefore be interpreted as indicating that the incoming quarterdiurnal at the mouth was gradually neutralized in its travel along the Thames by the locally generated component; by the time it reached sections 7 to 8 it was almost completely cancelled, and from there to the head of the river the locally generated tide dominated.

125. The rate at which this neutralization took place would depend upon many factors, and principally upon the range of the semi-diurnal tide. There would therefore be many possible variations in the profile of $Z 4$ and $\delta 4$ along the river, as Fig. 17 indicated.

126. The centrifugal effect mentioned by $\mathrm{Dr}$ McDowell as being of importance in the River Hooghly was almost certainly present, though to a lesser degree, in the Thames.

127. Whilst agreeing that a correction of the type suggested should not be overlooked when deducing friction parameters from water level observations, the Authors did not believe this phenomenon to be responsible for discrepancies in either their quarter-diurnal or mean level comparisons of computation with observation.

128. Of the gauge stations used in the Thames study, those at Greenwich (section 7.85) and Hammersmith (10.6) would seem to be most susceptible to a centrifugal effect (see Fig. 1); Greenwich was on an outer bend, Hammersmith on an inner. Fig. 18 showed the plotted values of $Z 0$ for a large spring tide; it would be seen that smooth curves could be drawn through them without undue discrepancies at either Greenwich or Hammersmith.

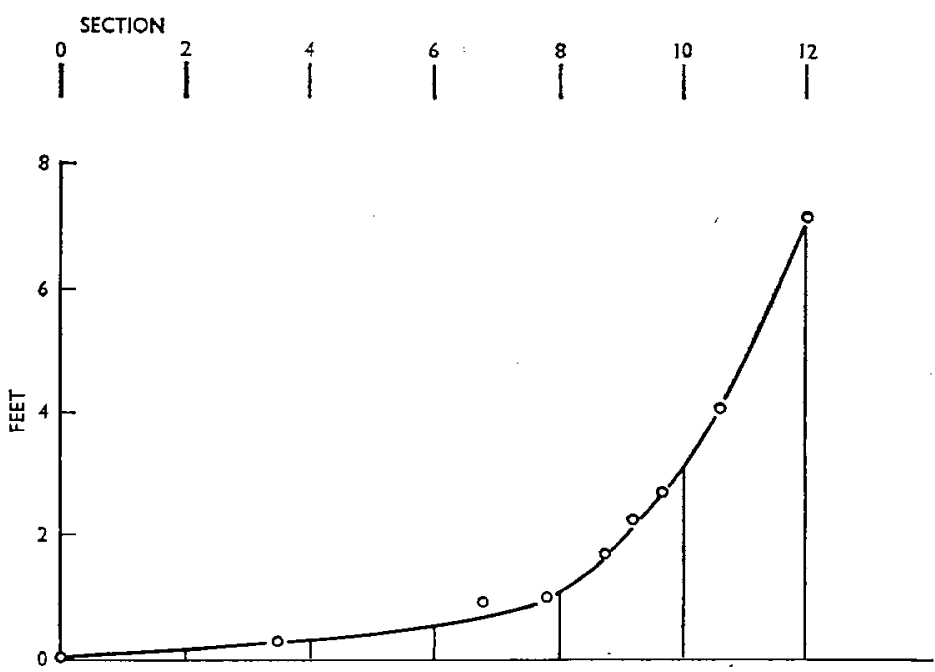

Fig. 18: Distribution OF OBSERVEd MEAN LEVEl ALONG The Thames, 4-5 MARCH, 1961

129. Dr McDowell had raised the problem of reflexion from an estuarine barrier affecting the seaward input. So far as the Authors were aware, Dr A. T. Doodson was the first to discern this effect in the results of a physical model of the Thames designed to study the consequences of a temporary barrier, One of the Authors 
$\left(\right.$ Rossiter $^{2}$ ), in a paper on numerical computations for a theoretical estuary approximating to the Thames, had written

'The need to specify the elevation at the mouth of the estuary effectively results in the suppression, at the mouth, of waves reflected outwards from the estuary. In the case of a purely tidal problem the specification can be assumed to include any such reflected wave, and so far as the fundamental semidiurnal tidal oscillation is concerned there is no mis-matching problem. The quarter-diurnal and higher species of tide are generated in the estuary proper, however, and it is to be expected that there will be some propagation of these species seawards. In the case of a transient oscillation such as a surge the mis-match can also be of importance, and indeed this difficulty is encountered in any method of injecting an input at the mouth of a tidal model, be it numerical, analogue or a small scale physical model.

For the purposes of this investigation the mis-match has been minimized by taking the estuary twice as long as it is in nature. The 'mouth' of the model estuary is thus somewhere in the vicinity of Lowestoft, the total length from mouth to barrier being approximately 117 miles. To a first approximation the speed of propagation of a free wave can be taken as $(g h)^{\frac{1}{2}}$, i.e. $32 \mathrm{ft} s^{-1}$. Thus for a disturbance to travel from Southend to the barrier, and back to the mouth where it is reflected by mis-matching, and arrive again at Southend, a total distance of 234 miles, would take some 11 hours. This interval of time is so long that mis-matching effects cannot materially influence the conclusions drawn from the computational results. A further safeguard in this respect is the decay experienced by any disturbance travelling seawards; an example of this effect is referred to in Section 12 and illustrated in Table 6 for a semidiurnal tide of period 12 hours.'

130. If this view was accepted it would seem that in this type of investigation numerical models might possess an advantage over physical models, since the latter were limited in size by the laboratory space available. The concept of a family of numerical models referred to earlier would seem to have considerable potential in such a context. The only alternative which had occurred to the Authors was the hypothetical extension seaward of an estuary model. A brief description of the use of such an approach for the Thames was given in $\S 120$.

131. In reply to Dr Barr, the effect of introducing the salinity term into the equation of motion was to raise the mean level over a tidal cycle. This rise increased steadily from zero at the mouth to $0.33 \mathrm{ft}$ at section 9 , and then decreased slightly to $0.22 \mathrm{ft}$ at the head. In terms of the time profile at section 9 the increase was greatest $(0.47 \mathrm{ft})$ at high water and least $(0.15 \mathrm{ft})$ at low water.

132. The fact that the introduction of a salinity term independent of time produced a time-dependent change in elevation was due to the fact that non-linear equations were used.

133. The Authors greatly appreciated the comments of Messrs Robson and Odd based on experiences derived from the numerical model of the River Nene, and wished to concentrate on their suggestion that the friction parameter be made a function of the velocity profile.

134. In $\S 98$ it was pointed out that the expression $u / u / \psi(\bar{H})$ was only an approximation to the term $\tau_{0} / \rho R$. In fact the latter term was itself derived by integrating the expression $(1 / \rho)(\partial \tau / \partial z)$ from bottom $(z=0)$ to surface $(z=\bar{H})$. Dissipative forces throughout the column of water were thus compounded into a single bottom friction term. In consequence, it was necessary to assume some velocity/depth distribution in order to relate the depth mean velocity (which appeared in other terms of the basic equations) to the bottom velocity (which appeared in the bottom friction terms). One of the justifications for accepting such a compound resistance was to be found in the good agreement it gave when applied to many observed data. 
135. Three important types of velocity distribution existed in natural estuaries:

(a) in tidal motion, where $\partial u / \partial z=0$ to a first approximation;

(b) in density currents, where the fresh water flow was concentrated near the surface, with or without a compensating saline counterflow at greater depth $(\partial u / \partial z=0)$;

(c) in wind drift, where the distribution depended greatly upon the time factor.

In nature a combination of all three distributions was to be expected; the information given by Robson and Odd for the Mersey and Ouse indicated a density current superposed on tidal flow.

136. In principle, the most satisfying way to handle such a complex case would be to go back to fundamentals, consider $u$ as a function of $x, z$, and $t$, and introduce the concept of eddy viscosity $(N)$ so that $(1 / \rho)(\partial \tau / \partial z)$ became $(1 / \rho)(\partial / \partial z)[(\rho N)(\partial u / \partial z)]$. A boundary condition, equivalent to the bottom friction term, would still be required, though it would not need to take account of conditions other than at the bottom.

137. A numerical model incorporating this approach could, in theory, compute the elevation and velocity structure in a tidal estuary subject to density currents and wind drift. Reliable values of $N$, however, were even scarcer than reliable values of the parameters used in bottom friction terms; many other problems would also have to be overcome. Thus in reply to the specific question posed in $\S 106$, the Authors commended the practice employed for the River Nene whereby the coefficient of bottom friction was adjusted empirically so as to take account of different velocity distributions.

138. Reference had been made to the advantages and flexibility of employing large computer installations in the solution of these numerical model problems. In recent work on the Thames Estuary, the Authors had in fact transferred the computations to the IBM 7094. The greatly increased capacity of this computer allowed the introduction of other facilities within the programme, notably a surface wind stress term. Flexibility had also been introduced with considerable advantage in reducing the bulk of input and output data. For example a subroutine capable of performing a Lagrangian interpolation for 11 intermediate points between successive terms in an input item allowed elevations, streams, wind speed, and direction to be input at hourly intervals only, whereas data representing fresh water flow and discharge from banks was input at intervals of 24 hours. Similarly the programme now offered a facility, through a further Lagrangian interpolation subroutine, to output data appropriate to gauging stations only, if this was to be preferred to data for each section of the model. The 7094 programme output data covering $100 \mathrm{~h}$ of real time in a matter of 0.8 minutes.

139. Mr Andrews's contribution to the discussion was concerned with the application of the method of characteristics to the solution of wave propagation along a channel. In fact Stoker, ${ }^{14}$ Schonfeld, ${ }^{15}$ and Dronkers ${ }^{4}$ had all shown that the method was applicable to more complex forms of the equations of motion and continuity than Mr Andrews suggested. Moreover, the technique might be extended to study wave motion which was time dependent in two dimensions.

140. The method of characteristics was of great value in gaining insight into wave motion, especially when discontinuities were present, but unless the characteristics were straight lines (in the special case when $u \pm \sqrt{ } g(h+\zeta)=$ constant), once the initial conditions were left behind neither the increments in time nor those in distance remained constant. For this reason the method of characteristics did not lend itself as readily to programming as did the initial value boundary method.

\section{REFERENCES}

8. LACEY G. Stable channels in alluvium. Proc. Instn civ. Engrs, 1930, 229 (Jan.), 373. (Author's reply to discussion.) 
9. Harder J. A. The prediction of tidal flows in canals and estuaries. Internal Rep., University of California. Part II, 1963.

10. Аввотт M. R. Salinity effects in estuaries. J. mar. Res., 1960, 18 (Oct.), 101-111.

11. Hoffman G. R. Tidal calculations applied to the estuary of the River Great Ouse. Proc. Instn civ. Engrs, 1954, 3 (Dec.), 809-829.

12. ACKERS P. Resistance of fluids flowing in channels and pipes. Hydraulics Res. Paper No. 1. London, H.M.S.O., 1958.

13. Dieter Rose. Uber die quantitative Ermittlung der Gezeiten und Gezeitenströme in Flachwassergebieten mit dem Differenzenverfahren. Mitt. FranziusInst., Hanover, 1960, 18, 1-59.

14. Stoker J. J. Water waves. New York, Interscience Publishers Inc., 1957.

15. Schonfeld J. C. Propagation of tides and similar waves. Dissertation, Delft (Ministere van Verkeer en Waterstaat), 1951. 